\title{
Phytoprotective compounds of non-traditional cereals
}

\author{
Magdaléna LACKO-BARTOŠOVÁ ${ }^{1}$ - Lucia LACKO-BARTOŠOVÁ² - L'ubomír KOBIDA ${ }^{1}$ \\ 1: Slovak University of Agriculture in Nitra, Tr. A. Hlinku 94976, E-mail: magdalena.lacko-bartosova@uniag.sk \\ 2: University of Economics in Bratislava, Dolnozemská cesta 1, 85235 Bratislava, \\ E-mail: lucialbartosova@gmail.com
}

Keywords: non-traditionl cereals, polyphenols, milling fractions

\section{Introduction}

The increasing demand for nutritionally heathy food products, the asserted therapeutic properties of foodstuff, the need for crop diversification have led to a renewed interest in ancient wheats such as einkorn, emmer or spelt (Arzani and Ashraf, 2017). Cereals are a good source of plant phenolics, the most common type of phenolic compounds in cereals are phenolic acids. Phenolics predominantly occur in the bran, i.e. the aleurone layer and outermost pericarp, which are usually eliminated during milling. In whole grain flours, the amount of polyphenols is highly variable and is mostly related to species and variety. Litte information is available on polyphenols in different Triticum species, as well as on possible environmental effects (Brandolini et al., 2013). The aim of this work was to explore differences in polyphenols concentration of different non-traditional cereals species, with focus on their free and bound fractions, distribution in different milling fractions, and changes caused by variable meteorological conditions.

\section{Materials and methods}

Winter spelt and emmer varieties were cultivated under organic farming conditions at Slovak University of Agriculture in Nitra $\left(48^{\circ} 19^{\prime} \mathrm{N}, 18^{\circ} 07^{\prime} \mathrm{E}\right)$ as randomised block experiment in four replicates during three consecutive growing periods. Experimental area belongs to warm agro-climatic region, arid subregion, with continental climate. After manual harvesting, the samples were de-hulled, grinded with FQC - 109 laboratory mill (Kapacitív Kkt., Hungary) The whole grain flour, flour and bran were taken to the analyses.

Phenolic extracts were prepared according to the method of Wang et al. (2013) with slight modification. Free and bound phenols were determined using Folin-Ciocalteu's method according to Van Hung et al. (2009) with some modification. After samples preparation, the absorbance of clear supernatants was measured at $765 \mathrm{~nm}$ using spectrophotometer UV-1800 (Shimadzu, japan). The content of free and bound phenols was calculated and expressed as ferulic acid equivalent (FAE) per gram of dry matter sample (DM). Analyses were carried out in four replicates. Collected data were subjected to multifactorial analysis of variance (ANOVA).

\section{Results and discussion}

One of the most occurring groups of phytochemicals in cereal grains are phenols. They are considered as a major group of compounds that contribute to the antioxidant activity of cereals. Phenols are often deficient in commercial wheat flours, because their highest concentrations are in aleuronic layers, endosperm, seed coat, which are usually eliminated by milling. The amount of phenols is highly variable and mostly related to species and varieties Adom et al., 2005). 
Statistical analysis confirmed significantly higher total phenols content of $T r$. dicoccon than in Tr. spelta in flour, whole grain flour and bran fraction Total phenols content in flour was $343.8 \mu \mathrm{g} \mathrm{FAE} \mathrm{g}^{-1} \mathrm{DM}$ for spelt, and $409.7 \mu \mathrm{g} \mathrm{FAE} \mathrm{g}^{-1} \mathrm{DM}$ for emmer, in whole grain flour the content was higher and accounted $1238.7 \mu \mathrm{g} \mathrm{FAE} \mathrm{g}^{-1} \mathrm{DM}$ for spelt and $1298.7 \mu \mathrm{g}$ FAE $\mathrm{g}^{-1} \mathrm{DM}$ for emmer. The highest content of total phenols was in bran $(5495.2 \mu \mathrm{g}$ FAE $\mathrm{g}^{-1} \mathrm{DM}$ in spelt; $6252.8 \mu \mathrm{g}$ FAE $\mathrm{g}^{-1} \mathrm{DM}$ in emmer). Bound phenols content represented $86.9 \%$ in spelt and $86.4 \%$ in emmer flour; in the whole grain flour the share of bound fraction was $86.3 \%$ in spelt and $86.4 \%$ in emmer, bound phenols were in bran fraction represented $76.9 \%$ in spelt and $78.5 \%$ in emmer.

\section{Conclusions}

In our study, more abundant source of phenols was Tr.dicoccon than Tr. spelta, higher concentrations of free, bound and total phenols were detected. Significant effect of growing year was recorded, low precipitations and higher temperature resulted in increased concentration of all phenols.

\section{Acknowledgement}

This research was supported by project ITEBIO „Support and innovations of special and organic products technologies for human healthy nutrition“, ITMS: 26220220115 implemented under Operational Programme Research and Development.

\section{References}

Arzani, A., Ashraf, M. (2017): Cultivated ancient wheats (Triticum spp.): a potential source of health-beneficial food products. Comprehensive Reviews in Food Science and Food Safety. 16: 477-488. DOI: http://dx.doi. org/10.1111/1541-4337.12262

Adom, K.K., Sorrells, M.E., Liu, R.H. (2005): Phytochemical and antioxidant activity of milled fractions of different wheat varieties. Journal of Agricultural and Food Chemistr. 53: 6. 2297-2306. DOI: http://dx.doi. org/10:1021/jf048456d

Brandolini, A., Castoldi, P., Plizzari, L., Hidalgo, A. (2013): Phenolic acids composition, total polyphenols content and antioxidant activity of Tr. monococcum, Tr. turgidum and Tr. aestivum: A two-years evaluation. Journal of Cereal Science. 58: 1. 123-131. DOI: http://dx.doi.org/10.1016/j.jcs.2013.03.011

Van Hung, P., Maeda, T., Miyatake, K., Morita, N. (2009): Total phenolic compounds and antioxidant capacity of wheat graded flours by polishing method. Food Research International. 42: 1.185-190. DOI: http://dx.doi. org/10.1016/j.foodres.2008.10.005

Wang, L., Yao, Y., He, Z., Wang, D., Liu, A., Zhang, Y. (2013): Determination of phenolic acid concentrations in wheat flours produced at different extraction rates. Journal of Cereal Science. 57: 1. 67-72. DOI: http:// dx.doi.org/10.1016/j.jcs.2012.09.013 